\title{
Drill core from seismically active sandstone gas reservoir yields clues to internal deformation mechanisms
}

Berend A. Verberne, Suzanne J. T. Hangx, Ronald P. J. Pijnenburg, Maartje F. Hamers, Martyn R. Drury and Christopher J. Spiers

Correspondence to: s.j.t.hangx@uu.nl

\section{This PDF file includes:}

Supplementary Text Sections S1-4 | Materials and Methods; Microscopes and Analysis Methods; Image Processing and Interpretation; Data Processing

Supplementary Figure S1 | Overview of core samples

Supplementary Figure S2 | Lab-test on an SDM-1 core sample (Sw14A) simulating productioninduced compaction

Supplementary Figure S3 | Slochteren Sandstone microstructures

Supplementary Figure S4 | Sectioned layered core samples

Supplementary Figure S5 | Intragranular crack density and descriptors quantifying the grain size distribution (GSD)

Supplementary Figure S6 | Hyperspectral cathodoluminescence (CL) mapping

Supplementary Figure S7 | Panchromatic cathodoluminescence (CL) mosaic

Supplementary Figure S8 | Electron backscatter diffraction (EBSD) mapping of quartz and Dauphiné Twin (DT) boundaries

Supplementary Table S1 | List of key data from sectioned ZRP-3a core samples

Supplementary Table S2 | List of key data from sectioned SDM-1 core samples (incl. Sw14A)

Supplementary Table S3 | Reactivated healed fractures

Supplementary Table S4 | Quartz area and Dauphiné Twin (DT) boundary length 


\section{S1. MATERIALS AND METHODS \\ S1.1 Core Samples and Sectioning}

We inspected core material from the depleted Zeerijp (ZRP)-3a and from the undepleted Stedum (SDM)-1 well at the core repositories of respectively Shell (Rijswijk, The Netherlands) and NAM (Assen, The Netherlands). We collected fragments from 35 depth intervals in the ZRP-3a core and from 33 depth intervals in the SDM-1 core (Fig. DR1). Samples selected for sectioning (Tables S1 and S2) were first flushed in daily refreshed demineralized water for several days, dried in a hot-air oven $\left(60^{\circ} \mathrm{C}\right)$, vacuum-impregnated using an epoxy resin, and then left to harden. Sections I to XVIII are $\sim 500 \mu \mathrm{m}$ thick polished sections prepared by D. Doran of the University of Southampton. All other sections are $\sim 30 \mu \mathrm{m}$ thin sections, prepared at Utrecht University. Polished sections were sputter-coated with a $\sim 4-6 \mathrm{~nm}$ thick layer of Pt/ Pd to enable conduction in a scanning electron microscope (SEM). In the case of loose sample fragments (Fig. 2B) a $\sim 10 \mathrm{~nm}$ thick layer was applied.

All sectioned samples (dimensions $2.5 \times 4.8 \mathrm{~cm}$ ) were imaged in full using SEM-backscatter electron (BSE) imaging (e.g., Fig. DR3). Each BSE mosaic is composed of up to 1800 highresolution BSE images. We chose BSE imaging over light microscopy because of the high quality and detail resolved, and the efficiency of (automatic) data collection. Sections $\mathrm{Sg} 07$ and Z22 were additionally mapped using electron dispersive X-ray (EDX) spectrometry, cathodoluminescence (CL) imaging and electron backscatter diffraction (EBSD), and sections Sw14 and Sw14A using only CL and EBSD. Prior to EBSD and CL mapping, sections were repolished using a silica colloid, rinsed, and then coated for 2 seconds using a glow-discharge Carbon evaporator.

\section{S1.2 Lab-Experiment}

The experiment consisted of a stress-relaxation test broadly following the procedure described by Pijnenburg et al., 2018, 2019a. Here we used a cylindrical plug, sample Sw14A, which was drilled in a direction parallel to the coring direction from core fragment Sw14 (undepleted SDM1 well, see Table S2). The experiment was carried out at a temperature of $100^{\circ} \mathrm{C}$, an effective confining pressure of $31 \mathrm{MPa}$, a pore pressure of $8 \mathrm{MPa}$ and a differential stress of $26 \mathrm{MPa}$, simulating the pressure-temperature conditions of the (depleted) Groningen reservoir (Pijnenburg et al., 2018, 2019; Van Eijs, 2015). Demineralized water (DMW) was used as the pore fluid. The sample was emplaced between two Mg-alloy (AZ-31), cylindrical, spacers, $15 \mathrm{~mm}$ long and 25 $\mathrm{mm}$ in diameter, which have elastic properties (Young's modulus $E=32 \mathrm{GPa}$, Poisson ratio $v=$ 0.35 ) close to those of the Slochteren Sandstone (i.e., $E \sim 10$ - $20 \mathrm{GPa}, v \sim 0.2$ ), thus reducing shear traction on the piston-sample interface during axial compression. To ensure an elastic response of the spacers at the conditions of testing they were pre-compressed at a differential stress of $105 \mathrm{MPa}$, at the same temperature and pressure conditions as used in the experiment. To reduce friction on the sample-piston interface further, we emplaced a double layer of thin (50 $\mu \mathrm{m})$ Teflon sheets. The Teflon sheets and Mg-alloy spacers were perforated to facilitate free pore fluid flow. The sample-spacer assembly was jacketed using a fluorinated ethylene propylene (FEP) sleeve, sealed against the top and bottom pistons using steel wire tourniquets. The completed assembly was emplaced into the pressure vessel, and heated to the desired testing temperature of $100^{\circ} \mathrm{C}$. During heating, a small confining pressure $\left(P_{\mathrm{c}}\right)$ was applied and maintained below the initial effective value of $5 \mathrm{MPa}$ used during testing. After evacuating the pore fluid system for 15 minutes, a pore fluid pressure of $2 \mathrm{MPa}$ was applied, followed by successive steps of increasing first the confining pressure, and then the pore pressure to their 
starting values of respectively $13 \mathrm{MPa}$ and $8 \mathrm{MPa}$, such that the effective confining pressure $\left(P_{\mathrm{c}}{ }^{\text {eff }}=P_{\mathrm{c}}-P_{\mathrm{p}}\right)$ never exceeded the starting value of $5 \mathrm{MPa}$. The sample was left to equilibrate at these conditions for 4 hours.

Starting from $P_{\mathrm{c}}=13 \mathrm{MPa}$, and $P_{\mathrm{p}}=8 \mathrm{MPa}$, the confining pressure was increased in $5 \mathrm{MPa}$ increment steps, while maintaining a constant pore pressure. Each pressurization step was followed by depressurization to the initial value of $P_{\mathrm{c}}{ }^{\text {eff }}=5 \mathrm{MPa}$. We employed a pressurization rate of $\pm 0.05 \mathrm{MPa} / \mathrm{s}$, chosen such that the rate of change of the mean effective stress was similar to that used during increase of axial stress. Upon achieving the desired confining pressure of 39 $\mathrm{MPa}$, hence an effective confining pressure of $31 \mathrm{MPa}, P_{\mathrm{c}}$ was held constant, while the sample was subjected to axial compression $\left(\sigma_{1}>\sigma_{2}=\sigma_{3}=\right.$ fixed $\left.P_{\mathrm{c}}\right)$. During axial compression, the loading piston was advanced, leading to an increase of the differential stress $\left(\sigma_{1}-\sigma_{3}\right)$ at a nearconstant axial strain rate $(\dot{\varepsilon})$ of $\sim 10^{-5} \mathrm{~s}^{-1}$, until the desired differential stress of $26 \mathrm{MPa}$ was achieved. Following piston arrest, a time-dependent decrease of the differential stress of about 1 to $3 \mathrm{MPa}$ occurred. To ensure sample equilibration at $\left(\sigma_{1}-\sigma_{3}\right) \approx 26 \mathrm{MPa}$, the sample was axially re-loaded to $\left(\sigma_{1}-\sigma_{3}\right)=26 \mathrm{MPa}, 30$ minutes after initial stress relaxation, and again after 70 hours. After a period of several days the differential stress remained constant within the resolution of measurement. Upon termination of the test, the sample was first axially unloaded $\left(\left[\sigma_{1}-\sigma_{3}\right]=0\right.$ $\mathrm{MPa}$ ), followed by depressurization to the initial $P_{\mathrm{c}}$ eff value of $5 \mathrm{MPa}$.

The internal axial load, sample temperature, confining pressure, pore pressure, pore fluid volume change, and axial displacement were logged at $2 \mathrm{~Hz}$ during piston advancement intervals, and at $0.1 \mathrm{~Hz}$ for $\sim 15$ mins into an interval of stress relaxation, using a 16-bit DAQPad National Instruments $\mathrm{A} / \mathrm{D}$ converter. All sensor voltage signals and displacement data were corrected using calibrations carried out under conditions relevant to those used during the test. During hydrostatic stress-cycles, the inelastic porosity change was obtained by dividing the inelastic change in pore volume, determined upon unloading to $P_{\mathrm{c}}{ }^{\text {eff }}=5 \mathrm{MPa}$, by the initial sample volume. Total shortening $(\Delta L)$ of the sample was determined from the difference in piston position between sample-piston touch upon the first axial loading, and final axial unloading, of the sample, at $P_{\mathrm{c}}^{\text {eff }}=31 \mathrm{MPa}$. The total inelastic axial strain is taken $\Delta L / L \times 100 \%$, where $L$ is the initial, unconfined length of the plug before the experiment, which was $53.20 \pm 0.05 \mathrm{~mm}$ as measured using calipers. The length of sample Sw14A after recovery from the experiment measured $53.10 \pm 0.05 \mathrm{~mm}$, implying a permanent axial shortening strain of $\sim 0.2 \%$, consistent with the mechanical data (Fig. DR3).

\section{S2. MICROSCOPES AND ANALYSIS METHODS}

Electron microscope imaging was conducted using an FEI Helios Nanolab G3 focused ion beam (FIB)-SEM, an FEI Nova Nanolab 600 FIB-SEM, a Phillips XL-30S SEM, and a JEOL JXA8530F electron microprobe, all installed at Utrecht University. Section-scale BSE micrograph mosaics were mapped in the Helios, using a concentric backscatter detector and FEI mapping software ("Maps"). Each mosaic-tile covers an area $1.18 \mathrm{~mm}$ x $0.79 \mathrm{~mm}$ with an overlap of $10 \%$ between each tile, and was recorded at a resolution of 1536x1024 pixels, at a working distance of 4-5 mm, using a dwell time of $3 \mu \mathrm{s}$, an acceleration voltage of $10 \mathrm{kV}$, and a beam current of $1.6 \mathrm{nA}$. During mapping we enabled automatic adjustment of focus and contrast/ brightness settings.

Element mapping by electron dispersive X-ray (EDX) spectrometry of sections Z22 and $\mathrm{Sg} 07$ was achieved using an Oxford Instruments (OI) X-Max 150 silicon drift detector installed on the Helios, employing an acceleration voltage of $10 \mathrm{kV}$, beam current of $1.6 \mathrm{nA}$, and a working 
distance of $4 \mathrm{~mm}$. Section-scale mosaics of the spatial element distribution were generated using the EDX operating software OI AZTec, for the elements $\mathrm{Al}, \mathrm{Ba}, \mathrm{Ca}, \mathrm{Cl}, \mathrm{K}, \mathrm{Fe}, \mathrm{Mg}, \mathrm{Na}, \mathrm{Mn}, \mathrm{S}$, and Si. These elements form the main constituents of the sectioned samples investigated here, except for $\mathrm{Cl}$, which we used to represent the background (noise) signal. Mosaic stitching was done within OI AZTec, and each single-element map was exported at 3937x9521 pixel resolution.

Section-scale CL mapping (Fig. DR7) was achieved using panchromatic detectors installed on the Helios (Gatan PanaCL), and on the XL-30S (KE Centaurus). Selected subareas (Fig. DR6) were additionally analyzed by hyperspectral mapping, using an xCLent IV CL spectrometry system installed on the electron microprobe. Using the Helios we employed an acceleration voltage of $10 \mathrm{kV}$, a beam current of $1.6 \mathrm{nA}$, while operating at a working distance of $7.4 \mathrm{~mm}$. The dwell time per pixel used was $10 \mu$ s for each image. Mapping was achieved using FEI "Maps", employing 10\% overlap between each tile. Each tile was recorded at 3072x2048 pixel resolution, covering an area $0.414 \times 0.276 \mathrm{~mm}^{2}$ in size $\left(1.34896 \cdot 10^{-7} \mathrm{~m} / \mathrm{pixel}\right)$. CL and BSE imaging in the microprobe occurs simultaneously, and was conducted using an acceleration voltage of $15 \mathrm{kV}$, a beam current of $30 \mathrm{nA}$, a dwell time of $10 \mathrm{~ms}$ and a step size of $0.5-1$ $\mu \mathrm{m} /$ pixel.

Electron backscattered diffraction (EBSD) data of sections Sg07, Z22, Sw14 and Sw14A were collected using a Nordlys EBSD detector mounted on the XL30S. Automatic mapping was conducted using OI AZtec operating software, at $20 \mathrm{~mm}$ working distance, using a $50 \mu \mathrm{m}$ aperture, an acceleration voltage of $30 \mathrm{kV}$, and a beam current of $2.4 \mathrm{nA}$. The step size for automatic mapping was $7.000 \mu \mathrm{m} /$ pixel for section $\mathrm{Z} 22$ and Sw14, $8.000 \mu \mathrm{m} /$ pixel for section Sw14A, and $8.167 \mu \mathrm{m} /$ pixel for section $\mathrm{Sg} 07$.

\section{S3. IMAGE PROCESSING AND INTERPRETATION}

Stitching of section-scale BSE mosaics was achieved using the grid/collection stitching plugin (Preibisch et al., 2009) developed for the open source, Java-based image processing software "ImageJ" (Schindelin et al., 2012). Conversion from pixel to length dimensions is done via the pixel resolution $\left(7.70833 \cdot 10^{-7} \mathrm{~m} / \mathrm{pixel}\right)$. To obtain levelled contrast between each tile we used a contrast-levelling batch routine (macro) in Adobe Photoshop 2014.1.0. CL micrographs collected using the Helios were first filtered using a bandpass fast-fourier transform built into ImageJ, while CL micrographs obtained using the microprobe did not require filtering. Crystallographic orientation data from EBSD measurements were processed using OI HKL Channel5, only indexing grains consistent with the quartz crystal system. We defined a grain boundary where crystal axes are mis-oriented by $>10^{\circ}$, and a Dauphiné twin when the crystal system is rotated $60^{\circ} \pm 2^{\circ}$ about the c-axis $<0001>$ (Tullis, 1970). We removed isolated pixels with a different (apparent) orientation, but a common crystal system to neighboring pixels. Zero-solutions were removed using an iterative nearest-neighbor interpolation.

Stitched BSE mosaics were cropped into domains of characteristic porosity, mineralogy, or grain size distribution (GSD), consistent with $\mathrm{mm}$ - to $\mathrm{cm}$-scale sedimentary layering identified from visual inspection. In all, we studied 51 domains in SDM-1 core samples, 56 in ZRP-3a core samples, and 7 in lab-deformed sample Sw14a (Tables S1 and S2). All image processing described below was carried out for each domain separately. The output result was visually inspected for consistency with the input image.

Intragranular crack mapping was achieved using a Wacom IntuosPro pen tablet connected to ImageJ or else to ESRI ArcMaps 2010, tracing each intragranular alignment of black pixels 
corresponding with a fracture. Crack mapping was done by multiple individuals, unaware of sample origin, and several maps or portions thereof have been reinterpreted to check reproduction. This revealed reproduction of the number of cracks in each map $\left(N_{c r}\right)$ to within $\pm 15 \%$, mainly due to interpretative ambiguities. The intragranular crack density $\left(\rho_{c r}\right.$ in Fig. 3a, Fig. DR6, and Tables S1 and S2) is calculated as $\rho_{c r}=N_{c r} /\left(\left(A_{m a p}(1-\phi)\right)\right.$, where $A_{\text {map }}$ is the area of the cropped BSE mosaic (i.e., the domain) used for preparing the crack map overlay, and $\phi$ is the pore area exposed in the mosaic.

Porosity was determined from thresholding of filtered BSE mosaics (Gaussian blur, pixel radius 2) using the Otsu algorithm (Otsu, 1979). Grain size was measured using the line intercept method, tracing 250 to $>1000$ line lengths $\left(N_{L}\right)$ across grains for each BSE mosaic, such that the standard error $S E=S D / \sqrt{ }\left(N_{L}\right) \leq 10 \mu \mathrm{m}$, where SD is the standard deviation of the grain size distribution. The intercept length $(l)$ is scaled via the pixel dimension and converted to grain size (d), using $d=1.5 \times 7.70833 \cdot 10^{-7} \times l$ (Dell'Angelo and Olgaard, 1995). In sections Sg07 and Z22, which were mapped using EDX, the phase-specific area was determined from summing the cumulative grain area in phase maps prepared from linear combinations of single-element maps ( $A_{\text {grain }}^{\text {phase }}$ in Fig. 3b) (Verberne and Spiers, 2017). To estimate the K-Feldspar grain area $\left(A_{\text {grain }}^{K F s}\right.$ in Fig. $3 \mathrm{c}$ and Tables S1 and S2), we carried out segmentation of the highest grey-level pixel intensities in BSE mosaics. In the Slochteren sandstone, the grains with the highest pixel intensity in BSE images are mainly K-Feldspar, with minor barite and siderite. Prior to segmentation, each mosaic was contrast-levelled, filtered (Gaussian blur, 2px), and subjected to a $3 \times 3$ convolution kernel to introduce artificial noise. Trial-and-error showed that this method improved the quality of the output. Segmentation was then carried out using the Multi-Otsu algorithm (Liao et al., 2001) in ImageJ, set to 4 threshold levels. The highest-level segment was filtered using a median ranking filter (15 px) to remove noise, and then converted to a binary image, such that the phase of interest is represented as white pixels against a black background. After removing isolated (black) pixels using the 'fill holes' command in ImageJ, the 'Analyze particles' routine was used, selecting particles of $\geq 3000 \mathrm{px}^{2}$ in size, effectively further filtering out random noise. Visual inspection showed a good match between the KFs grains of interest and the segmented output binary image. For each BSE mosaic or domain, a binary file representing the KFS grain area map is multiplied with its corresponding binary crack map. The resulting binary output shows lineaments, each of which represent a crack cutting KFs.

CL mosaics were referenced to the corresponding area in the BSE mosaic (using ESRI ArcMaps 10.3.1 or ImageJ), including the crack map and phase map overlay when available. Intergranular cracks identified in the crack map were inspected for overlap with preexisting healed fractures and overgrowths identified from the CL map. Maps of quartz area and Dauphiné Twins (DT's) prepared using EBSD and exported using OI HKL Channel5, were first converted to bitmaps (Fig. DR7). The quartz area and DT boundary length were calculated by taking the number of pixels in each map, and scaling via the step-size employed. The ratio of DT boundary length over the quartz area is taken to represent the DT density $\left(\rho_{D T}\right.$ in Table S3).

\section{S4. DATA PROCESSING}

S4.1 Student's T-Test Using KFs Crack Populations in ZRP-3a and SDM-1 samples Crack ratio $\left(\mu_{1}=N_{c r}^{K F s} / N_{c r}^{t o t}\right)$ data (Fig. 3c) can be treated as a discrete frequency distribution, $F(x)$, characterized by a population $(N)$, mean $(\bar{x})$ and standard deviation $S D$. We test the statistical discernibility between $F^{S D M}(x)$ and $F^{Z R P}(x)$ using an unequal variance, two-tailed ttest (Student, 1908) 


$$
t=\frac{x^{Z R P}-\bar{x}^{S D M}}{\sqrt{\frac{\left[S D^{Z R P}\right]^{2}}{N^{Z R P}}-\frac{\left[S D^{S D M}\right]^{2}}{N^{S D M}}}}
$$

Where the superscripts refer to data from respectively the SDM-1a and ZRP-3a cores. When $t$ falls below some reference value $\beta$, we may conclude that the distributions are statistically discernable at the $\beta$-level (or confidence level $(1-\beta) \times 100 \%)$ (Wonnacott and Wonnacott, 1990). Taking $H_{0}: \bar{x}^{S D M}=\bar{x}^{Z R P}$ and $H_{1}: \bar{x}^{S D M} \neq \bar{x}^{Z R P}$ returns a probability $P\left(T \leq t ; H_{0}\right)=0.056 \approx$ $6 \%$, implying that the null hypothesis must be overthrown at the $94 \%$ confidence level. This suggests that $\bar{x}^{Z R P}$ is indeed significantly larger than $\bar{x}^{S D M}$ —in line with the visual trend in Fig. $3 \mathrm{~B}$.

\section{REFERENCE CITED}

Dell'Angelo, L. N., and Olgaard, D. L., 1995, Experimental deformation of fine-grained anhydrite: Evidence for dislocation and diffusion creep: Journal of Geophysical Research: Solid Earth, v. 100, no. B8, p. 1542515440.

Liao, P.-S., Chen, T.-S., and Chung, P.-C., 2001, A Fast Algorithm for Multilevel Thresholding: Journal of Information Science \& Engineering, v. 17, p. 713-727.

Otsu, N., 1979, A Threshold Selection Method from Gray-Level Histograms: IEEE Transactions on Systems, Man, and Cybernetics, v. 9, no. 1, p. 62-66.

Pijnenburg, R. P. J., Verberne, B. A., Hangx, S. J. T., and Spiers, C. J., 2018, Deformation Behavior of Sandstones From the Seismogenic Groningen Gas Field: Role of Inelastic Versus Elastic Mechanisms: Journal of Geophysical Research: Solid Earth, v. 123, no. 7, p. 5532-5558.

-, 2019, Inelastic Deformation of the Slochteren Sandstone: Stress-Strain Relations and Implications for Induced Seismicity in the Groningen Gas Field: Journal of Geophysical Research: Solid Earth, v. 124, no. 5, p. 5254-5282.

Preibisch, S., Saalfeld, S., and Tomancak, P., 2009, Globally optimal stitching of tiled 3D microscopic image acquisitions: Bioinformatics (Oxford, England), v. 25, no. 11, p. 1463-1465.

Schindelin, J., Arganda-Carreras, I., Frise, E., Kaynig, V., Longair, M., Pietzsch, T., Preibisch, S., Rueden, C., Saalfeld, S., Schmid, B., Tinevez, J.-Y., White, D. J., Hartenstein, V., Eliceiri, K., Tomancak, P., and Cardona, A., 2012, Fiji: an open-source platform for biological-image analysis: Nature Methods, v. 9, no. 7, p. 676-682.

Student, 1908, The Probable Error of a Mean: Biometrika, v. 6, no. 1, p. 1-25.

Tullis, J., 1970, Quartz: Preferred Orientation in Rocks Produced by Dauphiné Twinning: Science, v. 168, no. 3937, p. 1342-1344.

Van Eijs, R., 2015, Neotectonic stresses in the permian Slochteren formation of the Groningen field: NAM.

Verberne, B. A., and Spiers, C. J., 2017, A Quantitative Microstructural Investigation of Depleted and Undepleted Reservoir Sandstones, 51st U.S. Rock Mechanics/Geomechanics Symposium: San Francisco, California, USA, American Rock Mechanics Association, p. 10.

Wonnacott, T. H., and Wonnacott, R. J., 1990, Introductory statistics, New York, USA, John Wiley \& Sons, Inc. 


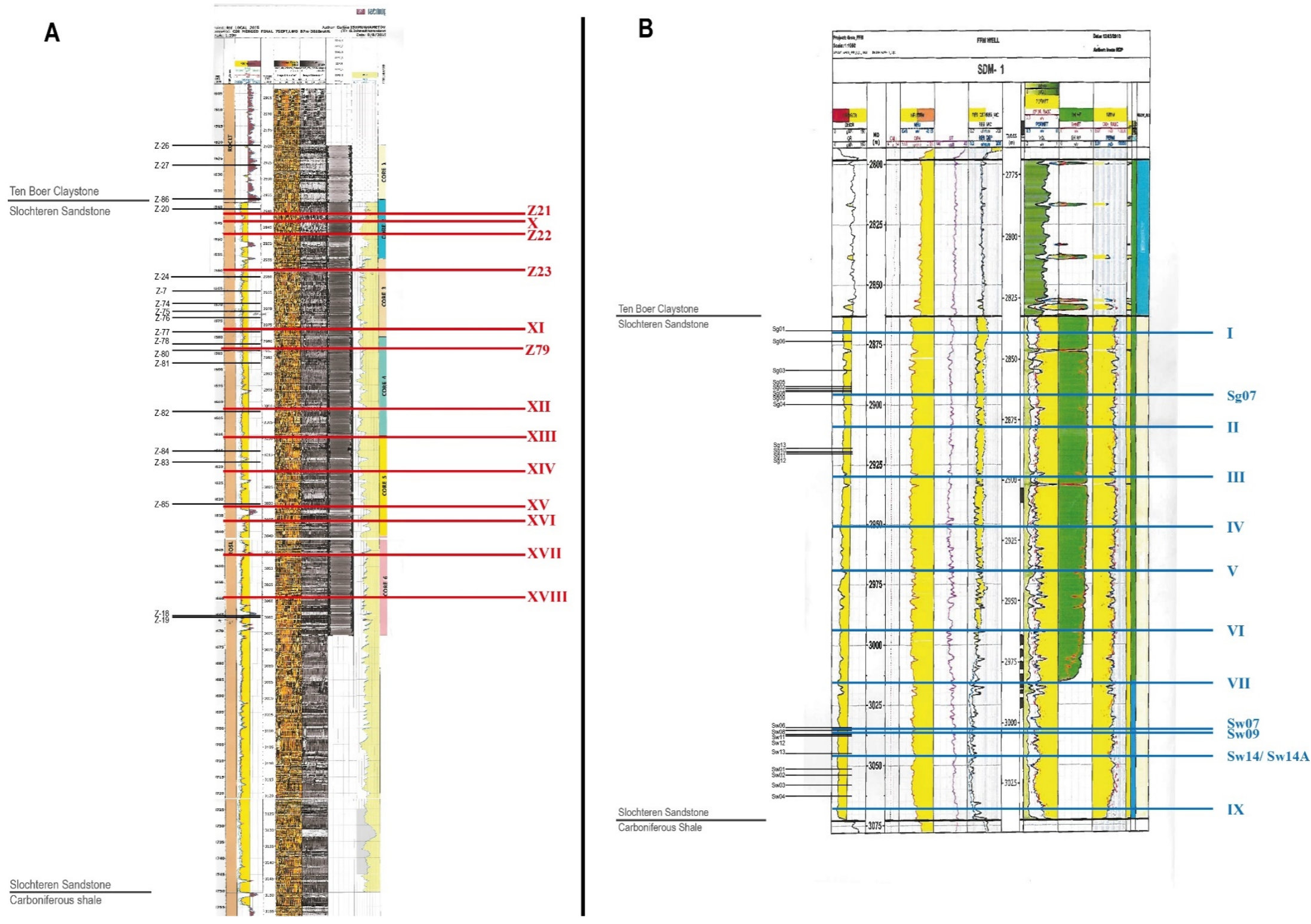

Figure S1. Overview of core samples. (A) Depleted ZRP-3a and (B) undepleted SDM-1 core. Sections in bold. 

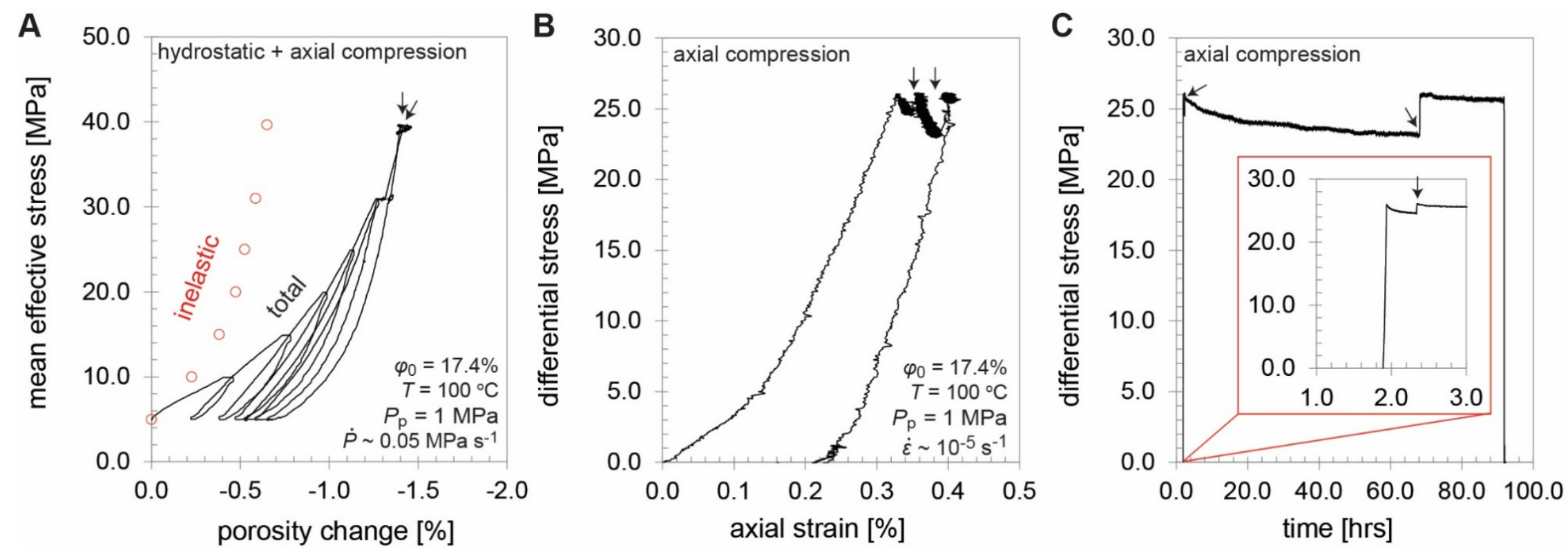

Figure S2. Lab-test on an SDM-1 core sample (Sw14A) simulating production-induced compaction. (A) Mean effective stress versus porosity change. (B) Differential stress versus axial strain, and (C) versus time. $\boldsymbol{\varphi}_{\mathbf{0}}=$ starting porosity, $T=$ temperature, $P_{\mathrm{P}}=$ pore fluid pressure, $\dot{\boldsymbol{P}}=$ pressurization rate, $\dot{\boldsymbol{\varepsilon}}=$ axial strain rate. Arrows indicate reloading to a differential stress of $26 \mathrm{MPa}$. 

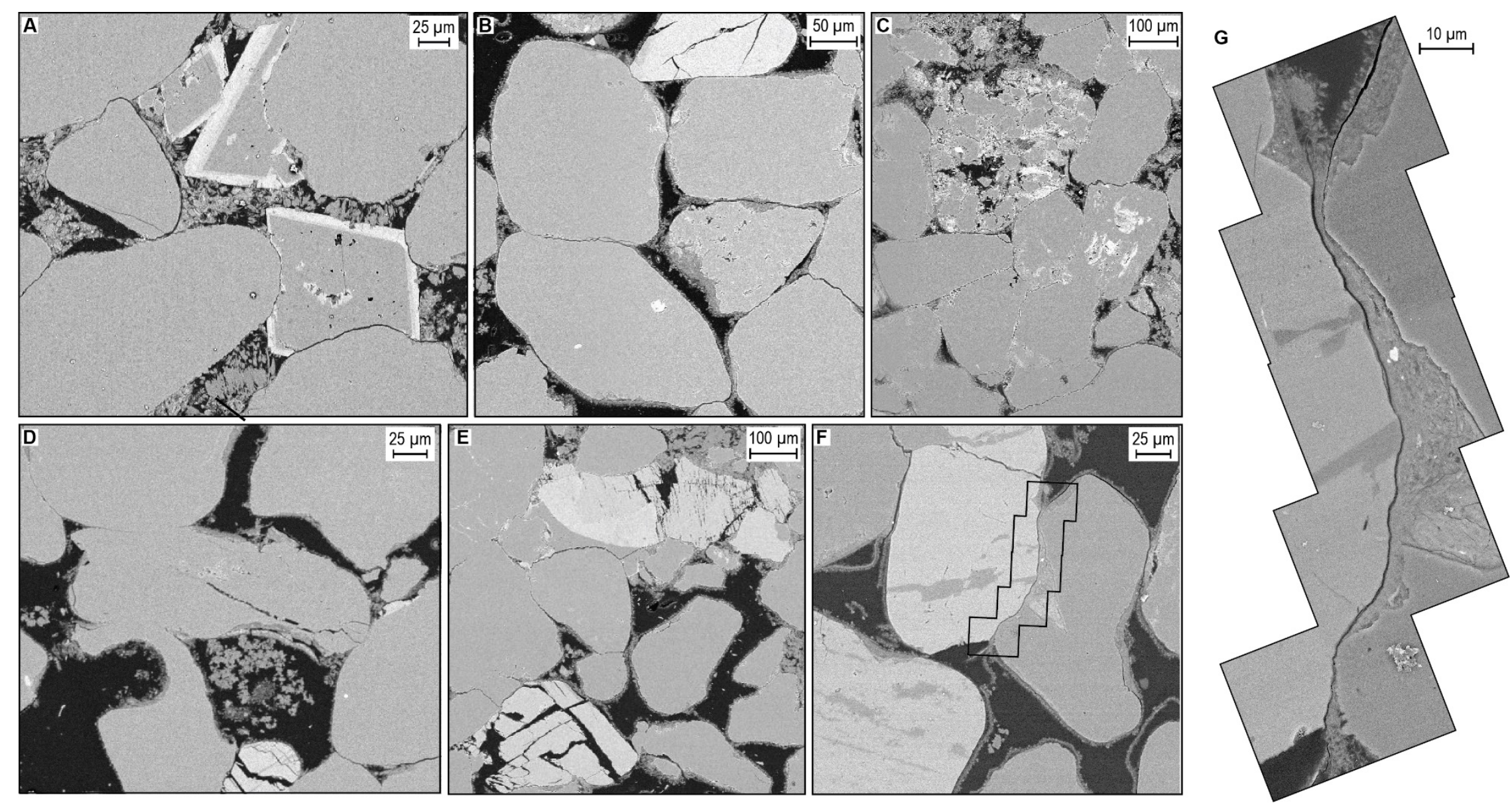

Figure S3. Slochteren Sandstone microstructures. Backscatter electron micrographs, representative for SDM-1 and ZRP-3a core. (A) Intragranular cracks in quartz and carbonate. Zoned crystals are ankerite/ dolomite with a siderite rim. (B) Clay-coated quartz grains and cracked K-feldspar (KFs) (bright grain). (C). Lithic fragment with high intragranular porosity. (D) Intragranular crack. (E) Multiple (cleavage) cracks in KFs. (F) and (G) Clay-rim within a KFs-quartz grain contact. 

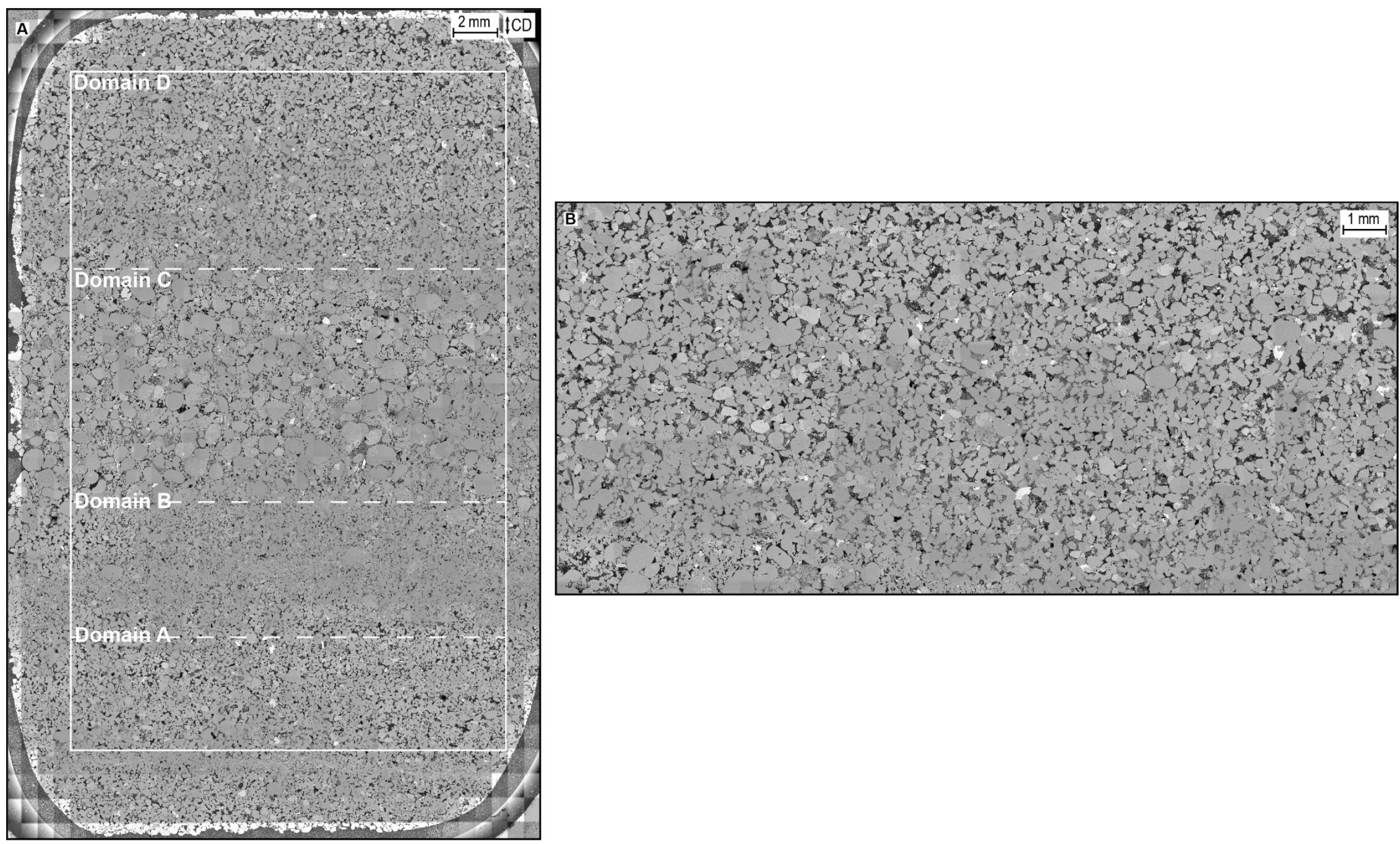

Figure S4. Sectioned layered core samples. (A) Backscatter electron micrograph mosaic of section 1 (SDM-1), highlighting domains A-D used for image analysis. (B) Domain "D". See Tables S1 and S2 for a list of all sectioned samples and domains. 

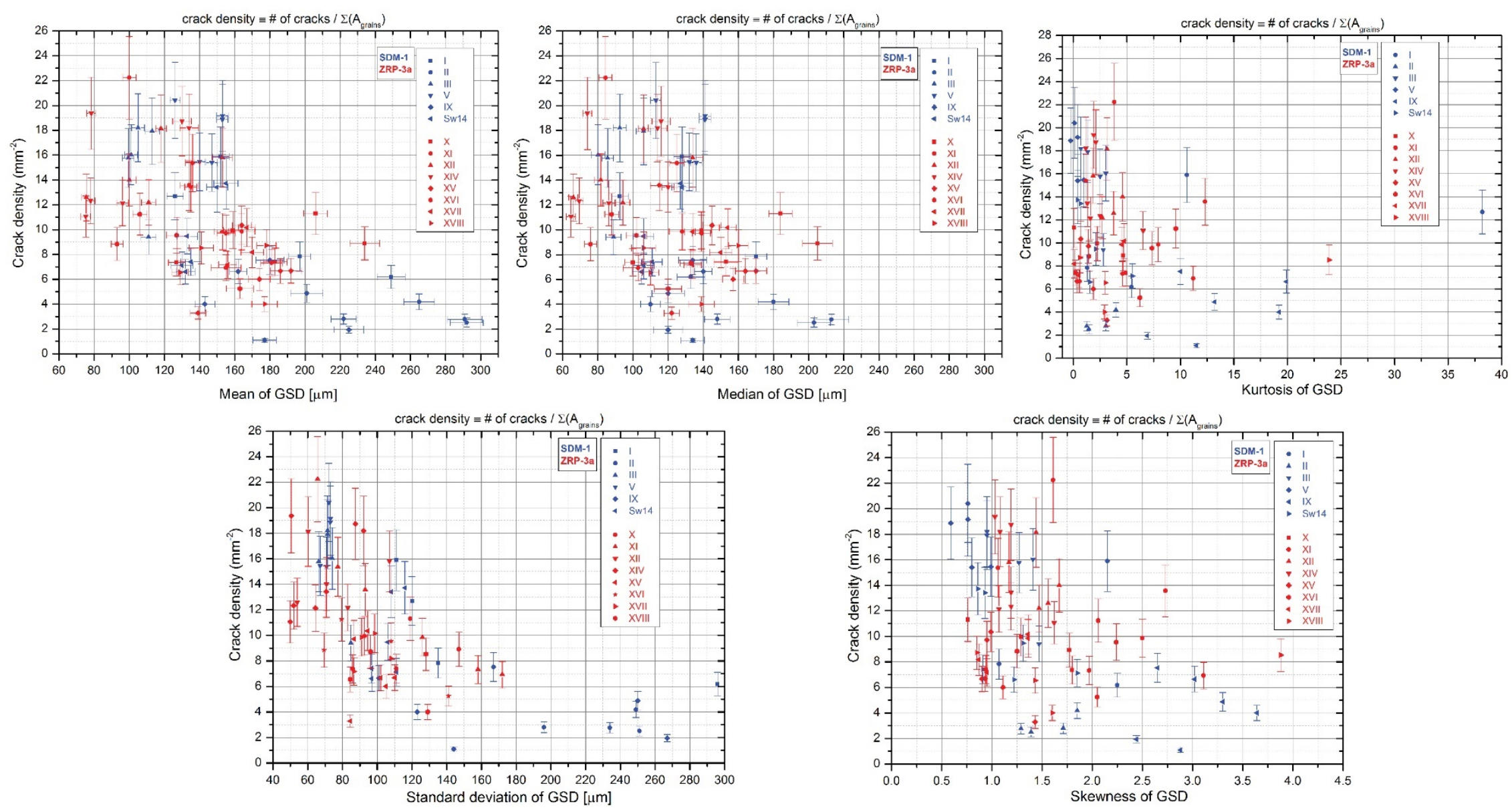

Figure S5. Intragranular crack density and descriptors quantifying the grain size distribution (GSD). Grain size data from linear intercept analysis and crack mapping of each domain (see Tables S1 and S2). 

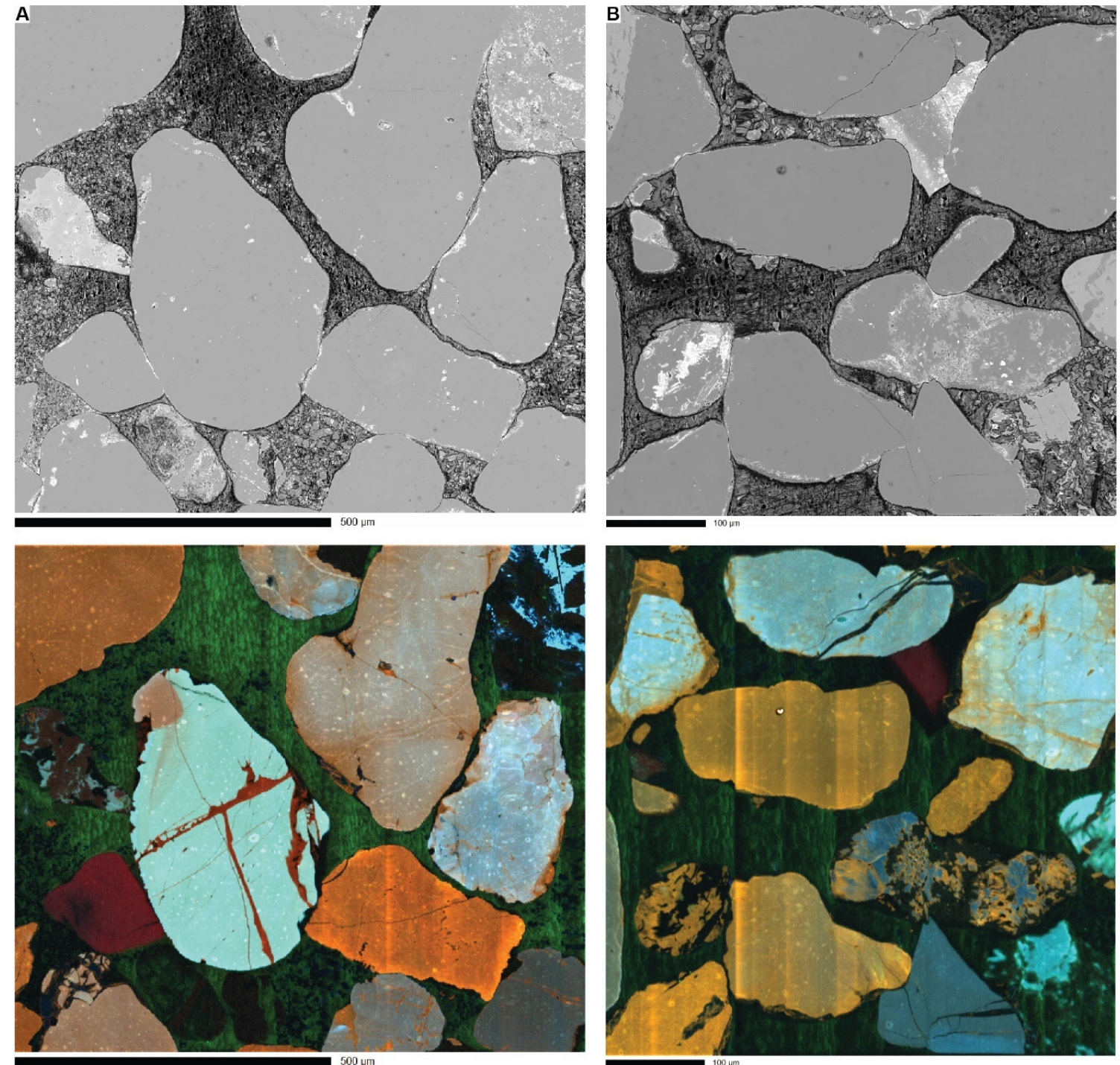

Figure S6. Hyperspectral cathodoluminescence (CL) mapping. The upper row shows backscattered electron micrographs, and the lower row the corresponding RGB CL maps. Collected from section Z22 (ZRP-3a). (A) Central quartz grain (blue CL) shows healed intragranular fractures and overgrowth (red and dark CL). (B) Central uppermost quartz grain shows a reactivated healed intragranular fracture (dark $\mathrm{CL}$ ). 


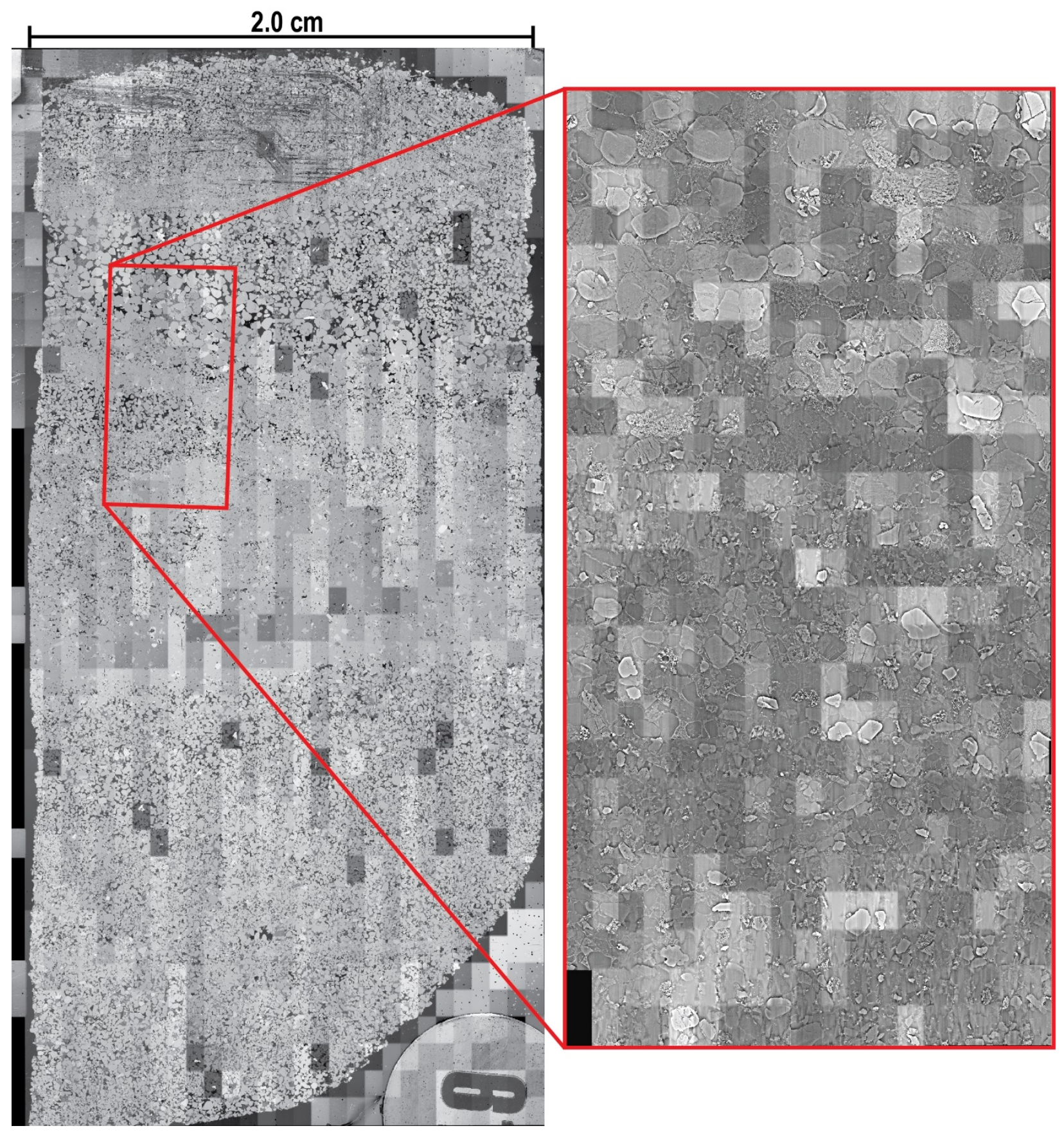

Figure S7. Panchromatic cathodoluminescence (CL) mosaic. A crack map overlay, prepared using the backscatter electron mosaic (left), was used to identify reactivated healed fractures in the CL mosaic (right). Section Z22 (depleted ZRP-3a core). 

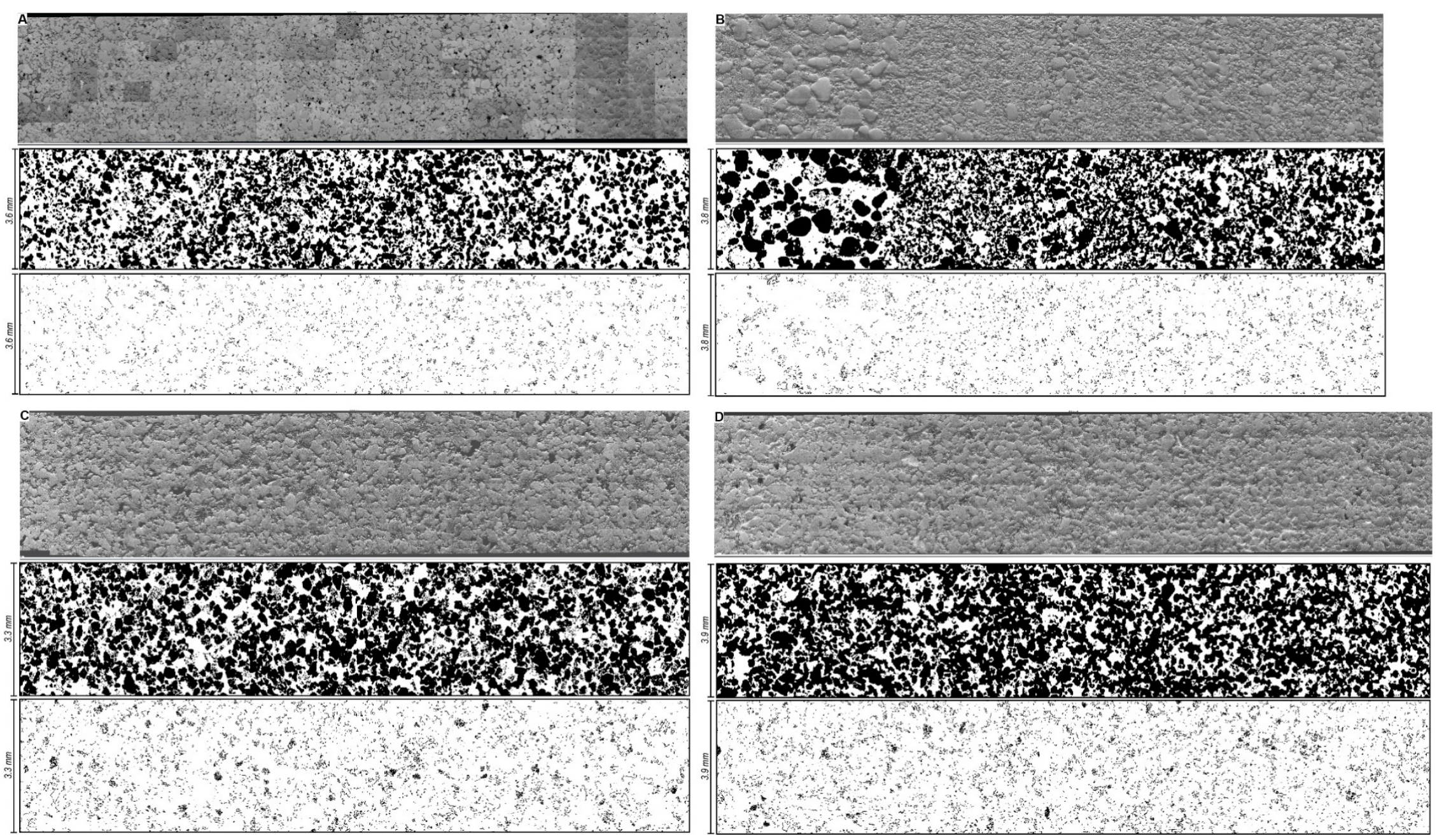

Figure S8. Electron backscatter diffraction (EBSD) mapping of quartz and Dauphiné Twin (DT) boundaries. The top image in each panel is a forescattered electron micrograph of the mapped area, the middle image the quartz area bitmap, and the bottom image the Dauphiné Twin boundary bitmap. 
Table S1. List of key data from sectioned ZRP-3a core samples.

\begin{tabular}{|c|c|c|c|c|c|c|c|c|c|c|c|c|c|c|c|c|}
\hline Section & TVD (m) & Domain & $\begin{array}{c}A_{\text {map }} \\
{\left[\mathrm{mm}^{2}\right]}\end{array}$ & $N_{c r}$ & $\begin{array}{c}\varphi \\
{[\%]}\end{array}$ & $\begin{array}{c}A_{K F s} \\
{\left[\mathrm{~mm}^{2}\right]}\end{array}$ & $N_{c r}{ }^{K F s}$ & $\begin{array}{c}\text { Median } \\
{[\mu \mathrm{m}]}\end{array}$ & $\begin{array}{c}\text { Mean } \\
{[\mu m]}\end{array}$ & $\begin{array}{c}S E \\
{[\mu m]}\end{array}$ & $\begin{array}{c}S D \\
{[\mu m]}\end{array}$ & Skew & Kurt & \multicolumn{3}{|c|}{$\begin{array}{c}\boldsymbol{\rho}_{c r} \\
{\left[\mathbf{m m}^{-2}\right]}\end{array}$} \\
\hline Z21 & 2941.4 & full & 286 & 5219 & 18.3 & 9.03 & 556 & $\mathrm{n} / \mathrm{a}$ & $\mathrm{n} / \mathrm{a}$ & $\mathrm{n} / \mathrm{a}$ & $\mathrm{n} / \mathrm{a}$ & $\mathrm{n} / \mathrm{a}$ & $\mathrm{n} / \mathrm{a}$ & 22.4 & \pm & 3.4 \\
\hline \multirow[t]{5}{*}{$\mathrm{X}$} & \multirow[t]{5}{*}{2943.5} & $\mathrm{~A}$ & 47.8 & 357 & 24.9 & 1.56 & 43 & 139 & 159 & 5.52 & 92.7 & 1.29 & 2.23 & 9.9 & \pm & 1.5 \\
\hline & & $\mathrm{B}$ & 73.2 & 611 & 26.2 & 2.94 & 71 & 184 & 206 & 6.71 & 119 & 0.76 & 0.08 & 11.3 & \pm & 1.7 \\
\hline & & $\mathrm{C}$ & 52.4 & 342 & 26.7 & 2.29 & 39 & 205 & 234 & 8.50 & 147 & 1.77 & 4.67 & 8.9 & \pm & 1.3 \\
\hline & & $\mathrm{D}$ & 21.5 & 120 & 24.1 & 0.51 & 11 & 100 & 127 & 4.69 & 85.8 & 1.80 & 4.91 & 7.4 & \pm & 1.1 \\
\hline & & $\mathrm{E}$ & 25.1 & 141 & 24.2 & 0.98 & 9 & 153 & 183 & 6.85 & 111 & 0.94 & 0.23 & 7.4 & \pm & 1.1 \\
\hline \multirow[t]{6}{*}{ Z22 } & \multirow[t]{6}{*}{2947.4} & 1 & 72.6 & 1008 & 19.2 & \multirow{6}{*}{$\mathrm{n} / \mathrm{a}$} & \multirow{6}{*}{$\mathrm{n} / \mathrm{a}$} & \multirow{6}{*}{$\mathrm{n} / \mathrm{a}$} & \multirow{6}{*}{$\mathrm{n} / \mathrm{a}$} & \multirow{6}{*}{$\mathrm{n} / \mathrm{a}$} & \multirow{6}{*}{$\mathrm{n} / \mathrm{a}$} & \multirow{6}{*}{$\mathrm{n} / \mathrm{a}$} & \multirow{6}{*}{$\mathrm{n} / \mathrm{a}$} & 17.2 & \pm & 2.6 \\
\hline & & 2 & 13.9 & 81 & 9.8 & & & & & & & & & 6.4 & \pm & 1.0 \\
\hline & & 3 & 31.5 & 428 & 17.4 & & & & & & & & & 16.4 & \pm & 2.5 \\
\hline & & 4 & 40.2 & 329 & 11.9 & & & & & & & & & 9.3 & \pm & 1.4 \\
\hline & & 5 & 46.8 & 143 & 6.1 & & & & & & & & & 3.3 & \pm & 0.5 \\
\hline & & 6 & 86.7 & 1172 & 19.5 & & & & & & & & & 16.8 & \pm & 2.5 \\
\hline \multirow[t]{2}{*}{ Z23 } & \multirow[t]{2}{*}{2958.5} & mos1 & 54.9 & 815 & 26.4 & \multirow{2}{*}{$\mathrm{n} / \mathrm{a}$} & \multirow{2}{*}{$\mathrm{n} / \mathrm{a}$} & \multirow{2}{*}{$\mathrm{n} / \mathrm{a}$} & \multirow{2}{*}{$\mathrm{n} / \mathrm{a}$} & \multirow{2}{*}{$\mathrm{n} / \mathrm{a}$} & \multirow{2}{*}{$\mathrm{n} / \mathrm{a}$} & & & 20.2 & \pm & 3.0 \\
\hline & & full & 287 & 6754 & 22.7 & & & & & & & $\mathrm{n} / \mathrm{a}$ & $\mathrm{n} / \mathrm{a}$ & 30.5 & \pm & 4.6 \\
\hline $\mathrm{XI}$ & 2976.6 & $\mathrm{~A}$ & 52.0 & 310 & 14.0 & 1.34 & 54 & 103 & 155 & 8.61 & 172 & 3.11 & 11.2 & 6.9 & \pm & 1.0 \\
\hline & & B & 29.2 & 355 & 21.0 & 0.73 & 38 & 125 & 136 & 3.98 & 77.3 & 1.06 & 1.18 & 15.4 & \pm & 2.3 \\
\hline & & $\mathrm{C}$ & 32.7 & 195 & 18.7 & 0.55 & 18 & 133 & 181 & 6.20 & 158 & 1.97 & 4.60 & 7.3 & \pm & 1.1 \\
\hline & & $\mathrm{D}$ & 44.7 & 484 & 20.2 & 1.04 & 54 & 115 & 134 & 5.11 & 93.1 & 2.73 & 12.3 & 13.6 & \pm & 2.0 \\
\hline & & $\mathrm{E}$ & 36.5 & 668 & 17.8 & 0.76 & 70 & 84.4 & 100 & 3.76 & 65.7 & 1.61 & 3.84 & 22.2 & \pm & 3.3 \\
\hline & & $\mathrm{F}$ & 25.1 & 202 & 18.4 & 0.78 & 25 & 128 & 164 & 7.47 & 126 & 2.50 & 7.93 & 9.9 & \pm & 1.5 \\
\hline Z79 & 2982.9 & full & 278 & 4810 & 14.8 & 7.76 & 526 & $\mathrm{n} / \mathrm{a}$ & $\mathrm{n} / \mathrm{a}$ & $\mathrm{n} / \mathrm{a}$ & $\mathrm{n} / \mathrm{a}$ & $\mathrm{n} / \mathrm{a}$ & $\mathrm{n} / \mathrm{a}$ & 20.3 & \pm & 3.0 \\
\hline XII & 3001.5 & A & 52.9 & 597 & 19.5 & 0.42 & 73 & 81.7 & 100 & 3.86 & 70.8 & 1.67 & 4.60 & 14.0 & \pm & 2.1 \\
\hline & & B & 55.1 & 676 & 22.5 & 0.68 & 42 & 134 & 153 & 5.63 & 107 & 1.17 & 1.85 & 15.8 & \pm & 2.4 \\
\hline & & $\mathrm{C}$ & 40.6 & 407 & 17.7 & 0.37 & 41 & 94.2 & 111 & 4.02 & 83.0 & 1.47 & 2.71 & 12.2 & \pm & 1.8 \\
\hline & & $\mathrm{D}$ & 10.9 & 116 & 15.3 & 0.07 & 9 & 66.1 & 75.5 & 2.54 & 53.9 & 1.56 & 3.77 & 12.6 & \pm & 1.9 \\
\hline & & $\mathrm{E}$ & 32.6 & 492 & 16.8 & 0.43 & 44 & 106 & 118 & 2.99 & 60.2 & 1.44 & 3.14 & 18.1 & \pm & 2.7 \\
\hline XIII & 3009.8 & $\mathrm{~A}$ & 43.8 & 77 & 14.0 & & & & & & & & & 2.0 & \pm & 0.3 \\
\hline & & $\mathrm{B}$ & 22.0 & 152 & 27.5 & & & & & & & & & 9.5 & \pm & 1.4 \\
\hline & & $\mathrm{C}$ & 12.6 & 112 & 28.1 & $\mathrm{n} / \mathrm{a}$ & $\mathrm{n} / \mathrm{a}$ & $\mathrm{n} / \mathrm{a}$ & $\mathrm{n} / \mathrm{a}$ & $\mathrm{n} / \mathrm{a}$ & $\mathrm{n} / \mathrm{a}$ & $\mathrm{n} / \mathrm{a}$ & $\mathrm{n} / \mathrm{a}$ & 12.4 & \pm & 1.9 \\
\hline & & $\mathrm{D}$ & 69.1 & 389 & 29.6 & & & & & & & & & 8.0 & \pm & 1.2 \\
\hline & & $\mathrm{E}$ & 18.1 & 161 & 28.1 & & & & & & & & & 12.4 & \pm & 1.9 \\
\hline XIV & 3020.6 & A & 11.5 & 109 & 14.6 & 0.16 & 10 & 64.7 & 75.2 & 2.73 & 49.9 & 1.62 & 6.52 & 11.1 & \pm & 1.7 \\
\hline & & B & 27.2 & 401 & 19.0 & 0.58 & 34 & 114 & 134 & 5.32 & 92.1 & 1.08 & 1.17 & 18.2 & \pm & 2.7 \\
\hline & & $\mathrm{C}$ & 19.5 & 315 & 16.7 & 0.42 & 22 & 74.0 & 78.3 & 2.50 & 50.5 & 1.03 & 1.91 & 19.4 & \pm & 2.9 \\
\hline & & $\mathrm{D}$ & 10.2 & 107 & 14.6 & 0.17 & 5 & 69.4 & 78.0 & 2.34 & 51.9 & 1.19 & 2.50 & 12.3 & \pm & 1.8 \\
\hline & & $E$ & 26.9 & 401 & 20.5 & 0.48 & 45 & 116 & 130 & 5.24 & 87.4 & 1.19 & 2.11 & 18.7 & \pm & 2.8 \\
\hline & & $\mathrm{F}$ & 28.8 & 289 & 17.2 & 0.29 & 18 & 86.3 & 96.2 & 3.33 & 64.4 & 1.07 & 1.60 & 12.1 & \pm & 1.8 \\
\hline & & $\mathrm{G}$ & 50.7 & 564 & 17.2 & 0.88 & 67 & 120 & 135 & 3.38 & 70.6 & 1.19 & 1.33 & 13.4 & \pm & 2.0 \\
\hline $\mathrm{XV}$ & 3032 & $\mathrm{~A}$ & 61.8 & 178 & 12.4 & 1.96 & 62 & 122 & 139 & 4.38 & 84.4 & 1.43 & 3.15 & 3.3 & \pm & 0.5 \\
\hline
\end{tabular}




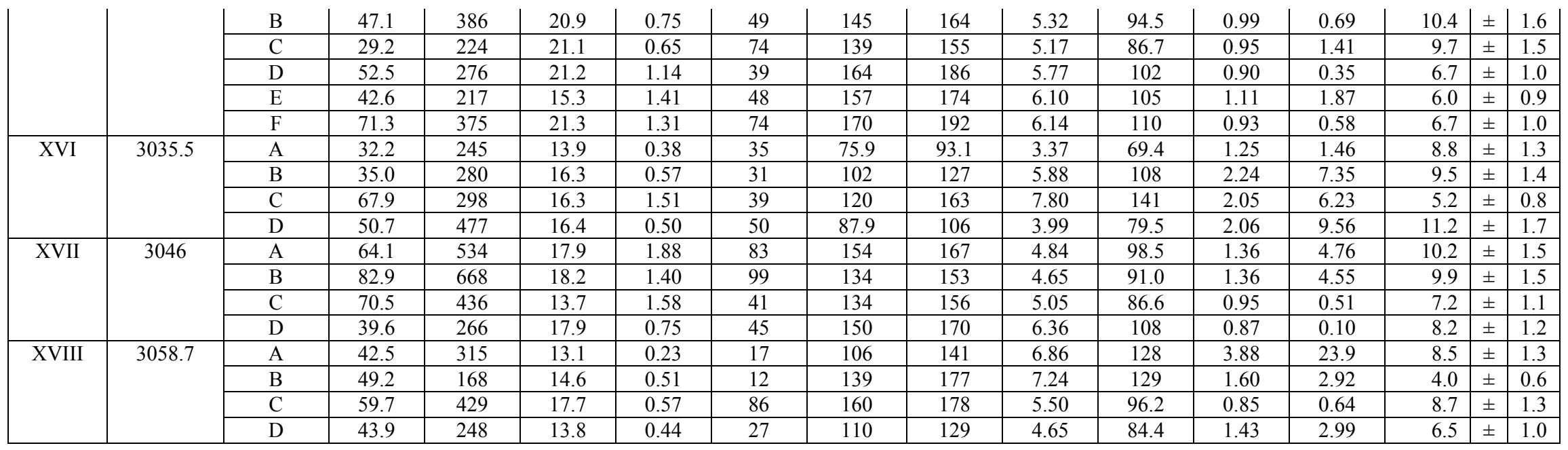

TVD $=$ True vertical depth; $A_{m a p}=$ area of (cropped) BSE mosaic. $N_{c r}=$ number of intragranular cracks. $\varphi=$ porosity. $A_{K F s}=$ cumulative area occupied by KFs grains. $N_{c r}{ }^{K F}=$ number of cracks in KFs grains. Median, mean, SE (standard error), SD (standard deviation), Skew(ness), and Kurt(osis) are quantitative descriptors of the grain size distribution. $\rho_{c r}=$ Intragranular crack density $\left( \pm 0.15 N_{c r}\right)$. 
Table S2. List of key data from sectioned SDM-1 core samples (incl. Sw14A).

\begin{tabular}{|c|c|c|c|c|c|c|c|c|c|c|c|c|c|c|c|c|}
\hline Section & TVD (m) & Domain & $\begin{array}{c}A_{\text {map }} \\
{\left[\mathrm{mm}^{2}\right]}\end{array}$ & $N_{c r}$ & $\begin{array}{c}\phi \\
{[\%]}\end{array}$ & $\begin{array}{c}A_{K F s} \\
{\left[\mathrm{~mm}^{2}\right]}\end{array}$ & $N_{c r}^{K F s}$ & $\begin{array}{c}\text { Median } \\
{[\mu \mathrm{m}]}\end{array}$ & 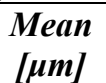 & $\begin{array}{l}\text { S.E. } \\
{[\mu m]}\end{array}$ & $\begin{array}{c}S D \\
{[\mu m]}\end{array}$ & Skew & Kurt & \multicolumn{3}{|c|}{$\begin{array}{c}\boldsymbol{\rho}_{c r} \\
{\left[\mathbf{m m}^{-2}\right]}\end{array}$} \\
\hline \multirow[t]{4}{*}{ I } & \multirow[t]{4}{*}{2840.6} & $\mathrm{~A}$ & 93.2 & 1201 & 18.9 & 3.50 & 125 & 128 & 152 & 4.73 & 111 & 2.15 & 10.6 & 15.9 & \pm & 2.4 \\
\hline & & $\mathrm{B}$ & 101 & 1102 & 14.1 & 2.11 & 87 & 92.5 & 128 & 4.73 & 128 & 4.31 & 33.2 & 12.7 & \pm & 1.9 \\
\hline & & $\mathrm{C}$ & 190 & 1022 & 13.1 & 4.47 & 68 & 133 & 249 & 7.98 & 296 & 2.25 & 5.44 & 6.2 & \pm & 0.9 \\
\hline & & $\mathrm{D}$ & 166 & 1063 & 18.3 & 6.82 & 182 & 170 & 197 & 6.19 & 135 & 1.07 & 1.30 & 7.8 & \pm & 1.2 \\
\hline \multirow[t]{2}{*}{$\mathrm{Sg} 05$} & \multirow[t]{2}{*}{2862.9} & $\operatorname{mos} 4$ & 38.7 & 573 & 24.7 & $\mathrm{n} / \mathrm{a}$ & $\mathrm{n} / \mathrm{a}$ & \multirow{2}{*}{$\mathrm{n} / \mathrm{a}$} & \multirow{2}{*}{$\mathrm{n} / \mathrm{a}$} & \multirow{2}{*}{$\mathrm{n} / \mathrm{a}$} & \multirow{2}{*}{$\mathrm{n} / \mathrm{a}$} & \multirow{2}{*}{$\mathrm{n} / \mathrm{a}$} & \multirow{2}{*}{$\mathrm{n} / \mathrm{a}$} & 19.7 & \pm & 3.0 \\
\hline & & full & 257 & 3679 & 23.0 & 17.4 & 799 & & & & & & & 18.6 & \pm & 2.8 \\
\hline \multirow[t]{7}{*}{ Sg07 } & \multirow[t]{7}{*}{2866.5} & 1 & 47.7 & 252 & 17.8 & \multirow{7}{*}{$\mathrm{n} / \mathrm{a}$} & \multirow{7}{*}{$\mathrm{n} / \mathrm{a}$} & \multirow{7}{*}{$\mathrm{n} / \mathrm{a}$} & \multirow{7}{*}{$\mathrm{n} / \mathrm{a}$} & \multirow{7}{*}{$\mathrm{n} / \mathrm{a}$} & \multirow{7}{*}{$\mathrm{n} / \mathrm{a}$} & \multirow{7}{*}{$\mathrm{n} / \mathrm{a}$} & \multirow{7}{*}{$\mathrm{n} / \mathrm{a}$} & 6.4 & \pm & 1.0 \\
\hline & & 2 & 122 & 414 & 10.5 & & & & & & & & & 3.8 & \pm & 0.6 \\
\hline & & 3 & 29.7 & 176 & 15.4 & & & & & & & & & 7.0 & \pm & 1.0 \\
\hline & & 4 & 48.7 & 292 & 15.4 & & & & & & & & & 7.1 & \pm & 1.1 \\
\hline & & 5 & 60.4 & 356 & 19.0 & & & & & & & & & 7.3 & \pm & 1.1 \\
\hline & & 6 & 85.4 & 436 & 17.3 & & & & & & & & & 6.2 & \pm & 0.9 \\
\hline & & 7 & 60.0 & 387 & 20.4 & & & & & & & & & 8.1 & \pm & 1.2 \\
\hline II & 2877.0 & $\mathrm{~A}$ & 78.6 & 194 & 10.9 & 2.42 & 49 & 213 & 291 & 9.82 & 234 & 1.29 & 1.25 & 2.8 & \pm & 0.4 \\
\hline & & B & 79.4 & 179 & 10.4 & 1.59 & 25 & 203 & 292 & 9.39 & 251 & 1.39 & 1.46 & 2.5 & \pm & 0.4 \\
\hline & & $\mathrm{C}$ & 62.1 & 238 & 8.6 & 2.75 & 51 & 180 & 265 & 8.75 & 249 & 1.85 & 3.98 & 4.2 & \pm & 0.6 \\
\hline & & $\mathrm{D}$ & 109 & 292 & 3.9 & 11.4 & 90 & 148 & 222 & 7.21 & 196 & 1.71 & 3.05 & 2.8 & \pm & 0.4 \\
\hline III & 2898.9 & A & 36.0 & 553 & 15.7 & 1.54 & 81 & 92.5 & 105 & 3.71 & 71.4 & 0.95 & 0.71 & 18.2 & \pm & 2.7 \\
\hline & & B & 17.8 & 247 & 13.4 & 0.80 & 41 & 80.2 & 101 & 3.78 & 74.0 & 1.41 & 3.04 & 16.0 & \pm & 2.4 \\
\hline & & $\mathrm{C}$ & 36.3 & 545 & 16.2 & 1.99 & 84 & 106 & 113 & 4.12 & 71.4 & 0.95 & 1.36 & 17.9 & \pm & 2.7 \\
\hline & & $\mathrm{D}$ & 23.0 & 194 & 10.2 & 1.00 & 29 & 89.0 & 111 & 4.32 & 84.8 & 1.47 & 2.80 & 9.4 & \pm & 1.4 \\
\hline & & $\mathrm{E}$ & 24.4 & 334 & 13.2 & 1.09 & 42 & 85.6 & 99.4 & 3.32 & 66.2 & 1.27 & 2.51 & 15.8 & \pm & 2.4 \\
\hline IV & 2950.6 & full & 574 & $\mathrm{n} / \mathrm{a}$ & 21.2 & 14.2 & $\mathrm{n} / \mathrm{a}$ & $\mathrm{n} / \mathrm{a}$ & $\mathrm{n} / \mathrm{a}$ & $\mathrm{n} / \mathrm{a}$ & $\mathrm{n} / \mathrm{a}$ & $\mathrm{n} / \mathrm{a}$ & $\mathrm{n} / \mathrm{a}$ & & $\mathrm{n} / \mathrm{a}$ & \\
\hline $\mathrm{V}$ & 2938.3 & $\mathrm{~A}$ & 51.9 & 842 & 20.5 & 0.81 & 61 & 113 & 126 & 2.94 & 72.2 & 0.76 & 0.11 & 20.4 & \pm & 3.1 \\
\hline & & $\mathrm{B}$ & 45.6 & 673 & 22.9 & 0.73 & 50 & 141 & 153 & 3.37 & 73.0 & 0.76 & 0.40 & 19.2 & \pm & 2.9 \\
\hline & & $\mathrm{C}$ & 18.0 & 225 & 19.0 & 0.18 & 11 & 132 & 140 & 3.17 & 67.1 & 0.99 & 0.97 & 15.5 & \pm & 2.3 \\
\hline & & $\mathrm{D}$ & 78.2 & 1145 & 22.4 & 1.31 & 111 & 141 & 153 & 3.24 & 72.9 & 0.59 & -0.24 & 18.9 & \pm & 2.8 \\
\hline & & $\mathrm{E}$ & 59.4 & 723 & 21.0 & 0.99 & 49 & 136 & 147 & 3.17 & 70.8 & 0.80 & 0.41 & 15.4 & \pm & 2.3 \\
\hline VI & 2960.3 & full & 533 & $\mathrm{n} / \mathrm{a}$ & 16.9 & 5.38 & $\mathrm{n} / \mathrm{a}$ & $\mathrm{n} / \mathrm{a}$ & $\mathrm{n} / \mathrm{a}$ & $\mathrm{n} / \mathrm{a}$ & $\mathrm{n} / \mathrm{a}$ & $\mathrm{n} / \mathrm{a}$ & $\mathrm{n} / \mathrm{a}$ & & $\mathrm{n} / \mathrm{a}$ & \\
\hline VII & 2985.6 & full & 597 & $\mathrm{n} / \mathrm{a}$ & 23.3 & 3.16 & $\mathrm{n} / \mathrm{a}$ & $\mathrm{n} / \mathrm{a}$ & $\mathrm{n} / \mathrm{a}$ & $\mathrm{n} / \mathrm{a}$ & $\mathrm{n} / \mathrm{a}$ & $\mathrm{n} / \mathrm{a}$ & $\mathrm{n} / \mathrm{a}$ & & $\mathrm{n} / \mathrm{a}$ & \\
\hline Sw07 & 3005.0 & full & 270 & 742 & 23.2 & $\mathrm{n} / \mathrm{a}$ & $\mathrm{n} / \mathrm{a}$ & $\mathrm{n} / \mathrm{a}$ & $\mathrm{n} / \mathrm{a}$ & $\mathrm{n} / \mathrm{a}$ & $\mathrm{n} / \mathrm{a}$ & $\mathrm{n} / \mathrm{a}$ & $\mathrm{n} / \mathrm{a}$ & 3.58 & \pm & 0.5 \\
\hline Sw09 & 3007.0 & full & 209 & 3446 & 10.9 & 1.13 & 99 & $\mathrm{n} / \mathrm{a}$ & $\mathrm{n} / \mathrm{a}$ & $\mathrm{n} / \mathrm{a}$ & $\mathrm{n} / \mathrm{a}$ & $\mathrm{n} / \mathrm{a}$ & $\mathrm{n} / \mathrm{a}$ & 18.5 & \pm & 2.8 \\
\hline Sw14 & 3015.4 & A & 49.9 & 306 & 13.9 & 0.09 & 3 & 106 & 130 & 6.14 & 111 & 1.85 & 5.52 & 7.1 & \pm & 1.1 \\
\hline & & $\mathrm{B}$ & 55.0 & 433 & 16.9 & 0.06 & 2 & 106 & 133 & 5.84 & 106 & 1.31 & 2.11 & 9.5 & \pm & 1.4 \\
\hline & & $\mathrm{C}$ & 17.5 & 104 & 10.1 & 0.10 & 3 & 105 & 132 & 5.42 & 96.8 & 1.22 & 1.55 & 6.6 & \pm & 1.0 \\
\hline & & $\mathrm{D}$ & 50.3 & 556 & 19.5 & 0.19 & 8 & 127 & 155 & 6.94 & 116 & 0.86 & 0.41 & 13.7 & \pm & 2.1 \\
\hline & & E & 36.0 & 240 & 10.1 & 0.11 & 1 & 111 & 135 & 5.73 & 96.7 & 0.91 & 0.25 & 7.4 & \pm & 1.1 \\
\hline & & $\mathrm{F}$ & 49.1 & 540 & 18.1 & 0.07 & 4 & 128 & 150 & 5.97 & 108 & 0.93 & 0.68 & 13.4 & \pm & 2.0 \\
\hline IX & 3041.1 & A & 65.8 & 67 & 6.8 & 0.23 & 2 & 134 & 177 & 6.60 & 144 & 2.88 & 11.5 & 1.1 & \pm & 0.2 \\
\hline
\end{tabular}




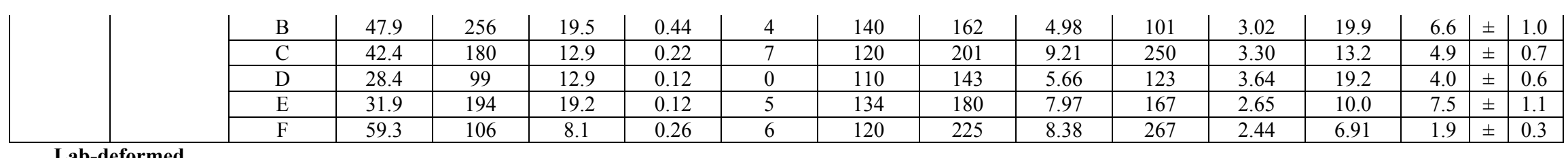

\begin{tabular}{|c|c|c|c|c|c|c|c|c|c|c|c|c|c|c|c|c|}
\hline \multirow{7}{*}{ Sw14A } & \multirow{7}{*}{3015.4} & $A$ & 611 & 479 & 130 & \multirow{7}{*}{$\mathrm{n} / \mathrm{a}$} & \multirow{7}{*}{$\mathrm{n} / \mathrm{a}$} & \multirow{6}{*}{$\mathrm{n} / \mathrm{a}$} & \multirow{6}{*}{$\mathrm{n} / \mathrm{a}$} & \multirow{6}{*}{$\mathrm{n} / \mathrm{a}$} & \multirow{6}{*}{$\mathrm{n} / \mathrm{a}$} & \multirow{6}{*}{$\mathrm{n} / \mathrm{a}$} & \multirow{6}{*}{$\mathrm{n} / \mathrm{a}$} & 00 & + & 14 \\
\hline & & $\mathrm{B}$ & 47.2 & 220 & 15.9 & & & & & & & & & 5.5 & \pm & 0.8 \\
\hline & & $\mathrm{C}$ & 19.8 & 92 & 11.2 & & & & & & & & & 5.2 & \pm & 0.8 \\
\hline & & $\mathrm{D}$ & 57.8 & 354 & 18.3 & & & & & & & & & 7.5 & \pm & 1.1 \\
\hline & & $E$ & 32.9 & 102 & 10.8 & & & & & & & & & 3.5 & \pm & 0.5 \\
\hline & & $\mathrm{F}$ & 62.6 & 404 & 17.2 & & & & & & & & & 7.8 & \pm & 1.2 \\
\hline & & G & 154 & 801 & 14.9 & & & 177 & 202 & 6.96 & 125 & 1.25 & 2.07 & 6.1 & \pm & 0.9 \\
\hline
\end{tabular}

TVD $=$ True vertical depth; $A_{\text {map }}=$ area of (cropped) BSE mosaic. $N_{c r}=$ number of intragranular cracks. $\varphi=$ porosity. $A_{K F s}=$ cumulative area occupied by KFs grains. $N_{c r}{ }^{K F s}=$ number of cracks in KFs grains. Median, mean, SE (standard error), SD (standard deviation), Skew(ness), and Kurt(osis) are quantitative descriptors of the grain size distribution. $\rho_{c r}=$ Intragranular crack density $\left( \pm 0.15 N_{c r}\right)$. 
Table S3. Reactivated healed fractures.

\begin{tabular}{llllll}
\hline Sample & Domain & $\begin{array}{c}\boldsymbol{A}_{\text {map }} \\
{\left[\mathbf{m m}^{-2}\right]}\end{array}$ & $\boldsymbol{N}_{\boldsymbol{c r}}$ & $\boldsymbol{N}_{\boldsymbol{c r}}$ heal & $\boldsymbol{X}$ \\
\hline Undepleted core & & & & & \\
Sw14 & B & 55.0 & 313 & 95 & 31.3 \\
& $\mathrm{C}$ & 17.5 & 114 & 51 & 44.7 \\
& $\mathrm{D}$ & 50.3 & 377 & 111 & 29.4 \\
Depleted core & $\mathrm{E}$ & 36.0 & 206 & 63 & 30.6 \\
XII & $\mathrm{A}$ & 52.9 & 405 & 124 & 30.6 \\
& $\mathrm{~B}$ & 55.1 & 533 & 149 & 28.0 \\
& $\mathrm{C}$ & 40.6 & 281 & 93 & 33.1 \\
Lab-deformed & D & 10.9 & 73 & 45 & 61.6 \\
Sw14A & & & & & \\
& D & 45.2 & 156 & 68 & 43.6
\end{tabular}

$A_{\text {map }}=$ total mapped area. $N_{c r}=$ number of intragranular cracks in quartz mapped. $N_{c r}^{\text {heal }}=$ number of cracks overlapping older healed fractures or overgrowths. $X=N_{c r}^{\text {heal }} / N_{c r} \times 100 \%$. 
Table S4. Quartz area and Dauphiné Twin (DT) boundary length.

\begin{tabular}{lcccl}
\hline Sample & $\begin{array}{l}\boldsymbol{A}_{\text {map }} \\
{\left[\mathbf{m m}^{-2}\right]}\end{array}$ & $\begin{array}{l}\boldsymbol{A}_{q t z} \\
{\left[\mathbf{m m}^{-2}\right]}\end{array}$ & $\begin{array}{l}\boldsymbol{L}_{\boldsymbol{D T}} \\
{[\mathbf{m m}]}\end{array}$ & $\begin{array}{l}\boldsymbol{\rho}_{\boldsymbol{D T}} \\
{\left[\mathbf{m m}^{-1}\right]}\end{array}$ \\
\hline Undepleted core & & & & \\
Sg07 & 80.7 & 44.1 & 417 & 9.44 \\
Sw14 & 54.0 & 30.0 & 504 & 16.8 \\
Depleted core & 73.6 & 33.3 & 354 & 10.6 \\
$\begin{array}{l}\text { Z-22 } \\
\text { Lab-deformed }\end{array}$ & 62.2 & 51.0 & 740 & 14.5 \\
Sw14A & & & \\
$A_{\text {map }}=$ total mapped area. $A_{q t z}=$ quartz area. $\rho_{D T}=$ DT density.
\end{tabular}

